\title{
SAÚDE PÚBLICA EM TEMPOS DE GUERRA: HOSPITAIS DO SESP E A SÃ POLÍTICA DE BOA VIZINHANÇA NAS CIDADE PARAENSES DE BREVES E SANTARÉM (1942-1945)
}

Edivando da Silva Costa ${ }^{1}$

\begin{abstract}
RESUMO
O presente artigo tem por objetivo analisar as políticas públicas direcionadas para as cidades paraenses de Breves e Santarém, durante o desenrolar da Segunda Guerra Mundial. Criado em 1942, o SESP Serviço Especial de Saúde Pública -, agência de iniciativa brasileira e norte-americana, iniciou um vasto programa de saúde e saneamento na região amazônica, com a instalação de estruturas médico-hospitalares apresentadas como novos modelos de atenção à saúde da população local. Analisaram-se, principalmente, como fontes documentais, jornais em circulação pelo país, relatórios e boletins produzidos pelo Serviço. Essas fontes revelam o esforço em representar uma região carente de estrutura médico-hospitalar e imersa à sua própria sorte, cuja redenção viria com as ações do SESP. Refletir de forma crítica sobre essas questões nos permitiu investigar compreensões sobre o Pará daquele contexto, os diferentes interesses políticos em jogo e a celebração da política de boa vizinhança entre Brasil e Estados Unidos.
\end{abstract}

Palavras-chave: SESP. Hospitais. Amazônia Paraense. Segunda Guerra.

\section{PUBLIC HEALTH IN TIMES OF WAR: SESP HOSPITALS AND THE SAFE GOOD NEIGHBOR POLICY IN THE STATE OF PARÁ CITIES OF BREVES AND SANTARÉM (1942-1945)}

\begin{abstract}
The purpose of this paper is to analyze public policies aimed to the Breves and Santarém cities in Pará, during the course of the Second World War. Created in 1942, SESP - Special Service for Public Health - , a Brazilian and North American initiative agency, started a vast health and sanitation program in the Amazon region, with the installation of medical and hospital structures presented as new models of care to the health of the local population. They were analyzed, mainly, as documentary sources, newspapers in circulation throughout the country, reports and bulletins produced by the Service. These sources reveal the effort to represent a region in need of a medical and hospital structure, and immersed in its own fate, whose redemption would come with the actions of SESP. Reflecting critically on these issues allowed us to investigate understandings about Pará in that context, the different political interests at stake and the celebration of the good neighborly policy between Brazil and the United States.
\end{abstract}

Keywords: SESP. Hospitals. Amazon of Pará. Second War.

Data de submissão: 20.04 .2021

Data de aprovação: 18.05 .2021

\section{INTRODUÇÃO}

Nos idos de 1942, ocorreu, no Rio de Janeiro, a III Conferência dos Chanceleres. Durante as reuniões, representantes do governo do Brasil e dos Estados Unidos firmaram uma série de acordos e, entre eles, a criação do SESP - Serviço Especial de Saúde Pública. A nova agência tinha como principal propósito atuar na área da saúde e saneamento da região amazônica. Segundo Campos (2000, p. 201) "para os Estados Unidos, a adesão do Brasil à

\footnotetext{
${ }^{1}$ Doutorando em História pela Universidade Federal do Pará (UFPA) e Professor de História da Escola de Aplicação da Universidade Federal do Pará (EAUFPA). E-mail: edivandoc@ufpa.br.
} 
causa dos Aliados tornou-se imperativa, sendo o projeto de saúde e saneamento vital para os interesses norte-americanos no Brasil". A Amazônia voltava a ser destaque no cenário nacional e internacional, tendo a borracha como figura central e o produto regional a ser explorado. Se no final do século XIX e início do XX, capitais como Belém e Manaus experimentaram "a riqueza criada pelo látex e a contribuição para uma reorganização do espaço urbano, sempre em função do mercado especializado da borracha" (SARGES, 2010, p. 114), a década dos anos 40 do século XX vai assistir aos esforços de uma política pública voltada sobretudo para as cidades do interior da Amazônia.

Nos anos iniciais do século XX, a questão da saúde pública ficou cada vez mais presente na agenda política e diplomática dos países e se acentuou no decorrer da Segunda Guerra Mundial, quando os Estados Unidos criaram agências de saúde com projeções internacionais. Segundo Cueto $(2015$, p. 12) "durante a maior parte dos séculos XIX e XX, o termo saúde internacional associou-se a acordos governamentais, disciplinas universitárias e programas sanitários em países pobres". Assim nasceria o SESP, uma agência bilateral, programada para atuar nas regiões mais pobres do Brasil, a priori na Amazônia, depois se estendendo país afora. Ainda na Conferência, ficou acordado que "a defesa do Hemisfério Ocidental requeria a mobilização das forças vitais, humanas e materiais, das repúblicas americanas, isto é, em áreas carentes de recursos médicos e sanitários, mas com potencial grande em recursos naturais" (BRASIL, 1944, p. 7). Não apenas o Brasil tornou-se alvo da política externa norte-americana. Como o interesse estava voltado também para a exploração dos recursos naturais, soava quase que imperativo a influência na saúde pública dos países vizinhos. Nesse contexto, os Estados Unidos se colocaram na dianteira na construção de uma agenda de saúde e saneamento para esses países.

Em vista disso, o artigo busca analisar as ações do Programa da Amazônia proposto pelo SESP nas cidades paraenses de Breves e Santarém, entre os anos de 1942 a 1945, momento de instalação de arquiteturas de saúde em algumas cidades do interior do Pará. Afinal, quais os limites e interesses de uma política pública de saúde, de iniciativa internacional em cooperação com o governo brasileiro, voltada para a Amazônia paraense em pleno contexto da Segunda Guerra Mundial? O que era Breves e Santarém nesse contexto? Quais as articulações entre os governos locais e os representantes do SESP para a instalação de hospitais nessas cidades? Como a imprensa e os meios informativos do Serviço se colocaram nesse debate? Que tipo de reação as estruturas médicas geraram nas comunidades locais? Responder a essas questões nos permite entender as políticas públicas direcionadas para a Amazônia em plena Guerra Mundial.

Visando a atingir os objetivos deste trabalho foi realizado levantamento, pesquisa e análise de documentos oficiais produzidos pelo SESP, sobretudo das atividades desenvolvidas na Amazônia paraense. Parte do acervo pesquisado se encontra nos arquivos e bibliotecas do Instituto Evandro Chagas, em Ananindeua no Pará e na Casa de Oswaldo Cruz - Fiocruz, no Rio de Janeiro. Tratam-se de fontes bastante dispersas pelo país e de certa maneira impõem dificuldades de acesso ao pesquisador. Bacellar (2005) aponta para os problemas enfrentados, de forma geral, aos serviços públicos: falta de pessoal, de instalações adequadas e de recursos. [...]. Aventurar-se pelos arquivos é sempre um desafio, [...] mas um esforço que quase sempre levará a alcançar resultados muito gratificantes. Também foram consultados jornais em circulação pelo país, como o periódico carioca O Jornal. Nele, foi possível observar como os noticiários estavam em sintonia com os discursos produzidos pelo SESP, com posicionamentos alinhados quanto a atuação da agência na Amazônia. A parcialidade de periódicos é alertada por Bacellar (2005, p. 63), para quem "documento algum é neutro, e sempre carrega consigo a opinião da pessoa e/ou do órgão que o escreveu". De posse da documentação, foi possível problematizar e buscar o entendimento das ações do Serviço e as intencionalidades postas em pauta. Conforme sugere Bloch (2001, p.79), "tudo o que o homem diz ou escreve, tudo que fabrica e toca pode e deve informar sobre ele". Em tempos de guerra, os meios de comunicações 
como boletins e jornais não demostravam neutralidade e eram utilizados para legitimar os projetos desenvolvidos pelo SESP a partir da parceria estabelecida entre Brasil e Estados Unidos.

\section{UM POUCO SOBRE OS HOSPITAIS}

O final do século XVIII trouxe um novo olhar e novos sentidos para os hospitais. De um espaço onde o personagem não era o doente que precisava de cura, mas o pobre que estava morrendo e deveria receber os últimos cuidados e o último sacramento, se tornaria o lugar do tratamento terapêutico, instrumento destinado a curar (FOUCAULT, 1995). "Nesse novo quadro o hospital tradicional perdeu espaço. Foi preciso transformá-lo física e conceitualmente, foi preciso que ele perdesse sua feição assistencial em benefício da terapêutica" (SANGLARD, 2006, p. 16).

Em meados do século XIX a história da saúde passa por importantes mudanças. Em alguns países europeus e nos Estados Unidos, o campo da medicina social direcionou-se para os problemas sanitários. É um período de novas descobertas que nortearam as bases teóricas da medicina, como os estudos patológicos e a proposição de novos meios de intervenção visando à contenção e à cura desse processo (SILVEIRA; FIGUEIREDO, 2011). As autoras advertem que no Brasil tais mudanças ocorreram no início do século XX e com ritmos diferentes entre as regiões. No Pará, a construção das primeiras arquiteturas hospitalares foi iniciativa das ações filantrópicas, a exemplo do hospital D. Luiz I da Benemérita Sociedade Portuguesa Beneficente do Pará, em 1877 e tinha como propósito dar assistência aos portugueses no combate às epidemias que assolavam a capital paraense (FIGUEIREDO, 2018). Por longos anos, os hospitais "tiveram um papel atrelado à ideia de caridade, espaço para receber doentes pobres que por motivações diversas viam-se reféns das mais diversas doenças" (GOMES, 2019, p. 21).

Na segunda metade do século XIX outras arquiteturas hospitalares foram construídas com o objetivo de dotar a cidade de melhores condições de higiene, baseando-se nas teorias médicas e sanitárias vigentes, como o hospital Juliano Moreira e hospital Domingos Freire. Nesse período, as epidemias de febre amarela e varíola geraram as primeiras medidas saneadoras na cidade, com a proibição de enterramentos nas igrejas e com isso, a construção dos cemitérios da Soledade e de Santa Isabel (MIRANDA, 2018). Ainda segundo Miranda (2018, p. 81), sendo uma população muito pobre dependiam da "compaixão e caridade das pessoas [...]. As irmandades, beneficências e misericórdias, instituições lusas de caridade eram responsáveis por grande parte da história da saúde de Belém". A Santa Casa de Misericórdia está entre as instituições com atuação nas ações de saúde na capital do Pará surgida no seio das irmandades. Fundada em 1650, funcionou como irmandade até 1890, quando passou a ser Associação Civil de Caridade e transformou-se em Fundação em 1990, passando a ser financiada pelo governo do estado (MIRANDA et al., 2015).

$O$ processo de institucionalização da assistência à saúde no Pará ocorreu na virada do século XIX para o XX. Na capital paraense, as inaugurações dos hospitais São Sebastião e Domingues Freire, associados à medicina moderna, representaram o avanço na área da saúde pública da cidade. Os hospitais impulsionaram uma nova fase das políticas públicas, onde práticas ligadas à caridade, embora não desaparecessem, sediaram espaço à ciência médica na estrutura hospitalar (RODRIGUES, 2021). Mesmo institucionalizado, o saber médico no Pará concentrou suas atenções em Belém, em detrimento do interior do Estado. "Durante quase toda a Primeira República, vale dizer, os moradores do interior raramente viram médico e farmacêutico passarem por suas vilas e povoados" (RODRIGUES, 2021, p. 202). Em meados da década de 1920, existiam alguns postos de saúde, espalhados por algumas cidades do interior, tendo como base ações voltadas para a profilaxia ao paludismo e as verminoses, além 
de oferecer serviços como pequenas cirurgias, vacinação e conferências de educação sanitária (VIEIRA, 2016).

Nos idos de 1943, uma equipe de engenheiros sanitaristas do SESP percorreu algumas cidades da Amazônia com o intuito de fazer o levantamento de um inquérito e observar as condições sanitárias locais. A par desses dados, o objetivo seria "elaborar um eficiente programa de saneamento" (MIRANDA; TABOSA, 1948, p. 689). Jornais em circulação pelo país divulgavam as ações realizadas na Amazônia e divulgavam quase diariamente os planos de trabalhos do Programa reforçando aos leitores a parceria existente entre Brasil e Estados Unidos e a luta travada contra as doenças. Em um longo texto, $O$ Jornal noticiava a cooperação do Estado com os municípios para a execução das obras. Os planos teriam sido enviados ao interventor federal e previam ações como, "a construção de postos de higiene, [...] sub-postos, [...] hospitais, [...] construção de sanatórios e abastecimento de água em lugares do interior a serem feitos pelo SESP em cooperação com o Estado e município" (FUNCIONARÃO, 1945, p. 6). Se as instalações assumiam caráter de serviço permanente, também se constituíam como modelos de intervenções e de controle sobre a população, principalmente nas práticas médicas e de higiene, sobre os hábitos e costumes locais.

No contexto da Segunda Guerra Mundial, muitos "soldados da borracha" foram enviados para o interior com o intuito de extrair o látex tido como essencial dentro dos esforços de guerra. Como forma de justificar as ações na região, buscou-se descredenciar as condições médicas locais, ao apresentar "o estado do Pará e, de um modo geral, em todo o Vale Amazônico, os Postos de Higiene constituíam os únicos recursos médicos da cidade" (BRASIL, 1942-1945, p. 9). Esse fato serviu como justificativa para a implantação dos hospitais tidos como modernos e os cuidados com a saúde dos trabalhadores, colocando-os como responsáveis pelo atendimento à saúde básica da população. Embora estivesse presente em vários municípios, uma série de exigências eram feitas para a instalação dessas estruturas, e não se tratavam apenas de uma simples solicitação da prefeitura, mas impunham algumas obrigações para o poder público local, em geral, com a doação de terrenos, aproveitamento de prédios já existentes e a contribuição em soma de dinheiro.

\section{A SÃ POLÍTICA DE BOA VIZINHANÇA}

A instalação do SESP a partir da celebração dos acordos bilaterais entre Brasil e Estados Unidos era justificada pela necessidade de se estabelecerem esforços conjuntos na luta e combate contra as doenças. Segundo o norte-americano George Dunham, os serviços Cooperativos Interamericanos de Saúde Pública foram organizados para ajudar o fortalecimento da "política de boa vizinhança, num momento em que a ameaça de conquista alemã era mais séria e se tornava necessária todos os meios possíveis para combater a influência do Eixo nas Américas" (BRASIL, 1944, p. 7). A prática de promoção de saúde a partir de laços cooperativos possuía um alvo em comum, sendo, ao mesmo tempo, os países alinhados ao "Eixo" e os mosquitos os grandes adversários a serem combatidos. Estratégia sanitária foi como o jornal carioca Diário da Noite se referiu à criação do SESP. Para o periódico, a agência "resultou de um dos acordos de Washington e trazia, na hora penosa da guerra, um instrumento de boa vizinhança e por isso seu custeio resulta de contribuições de brasileiros e norteamericanos" (ESTRATÉGIA, 1943, p. 1). Nesse ínterim, os Estados Unidos, além de se colocarem na dianteira do processo como os responsáveis na condução das ações na luta contra os inimigos, propagavam a ideia de que os países vizinhos eram dependentes de auxílio e proteção contra os adversários.

O Brasil vivia os anos do chamado Estado Novo, período em que a administração de Getúlio Vargas instituiu um governo ditatorial que, por meio de uma Constituição autoritária possuía, como uma das orientações, o controle social através da presença de um Estado forte 
comandado por um líder carismático, capaz de conduzir as massas no caminho da ordem (CAPELATO, 2007).

A aproximação do Brasil com os Estados Unidos foi uma jogada política estratégica, isto é, Getúlio Vargas buscou tirar vantagens do governo norte-americano, para que uma aliança fosse possível com aquele país. Segundo Delmo Arguelhes (2015, p. 74), a "política externa de Vargas é tida como pragmática e exemplar. Ele teria conduzido a aproximação do Brasil com os Estados Unidos de modo a extrair o máximo de vantagens". A neutralidade bélica sustentada pelo Brasil em pleno curso da guerra chegaria ao fim, pois a reunião dos Ministros das Relações Exteriores das Repúblicas Americanas "não foi apenas o momento temporal que marcou o fim da neutralidade brasileira, mas através de negociações sutis com o governo norte-americano, alimentou-se um sonho, uma projeção mundial de nação" (ARGUELHES, 2015, p. 75).

Tendo sido criado em tempos de guerra, o IAIA - Instituto de Assuntos Interamericanos - desenvolvia suas atividades ligadas aos esforços para abastecimento durante o combate, e sua atuação ocorria principalmente nas áreas de interesse na produção de recursos minerais. De acordo com o presidente, o General George Dunham, "milhares de trabalhadores estavam ativamente empenhados na produção de cobre, manganês, chumbo, borracha, fibras, quinino, madeira e outros materiais importantes para o esforço de guerra" (BRASIL, 1944, p. 1). A demanda por trabalhadores sadios e aptos para a exploração dos produtos naturais fomentou iniciativas para a instalação de uma rede de saúde, além de exaltar o papel desempenhado pelos profissionais de saúde, pois "por trás das curvas de produção, havia uma emocionante história do trabalho humano. Médicos e engenheiros sanitários se desdobram em esforços para manter esses homens saudáveis e felizes" (BRASIL, 1944, p. 1). $\mathrm{Na}$ fala do general, os trabalhadores ligados à exploração das riquezas naturais, seriam figuras indispensáveis para a concretização da vitória na guerra e, suas atividades essenciais, mesmo que a batalha fosse em outro campo, pois, "na produção complexamente constituída da guerra total, a permanente vigilância contra a doença torna-se o preço necessário da saúde, como o é da liberdade" (BRASIL, 1944, p. 1).

Política de boa vizinhança e programas cooperativos passaram a ser temas explorados ao longo da guerra e estavam presentes nas mensagens de vários profissionais que atuaram no SESP. Criada durante a Conferência Pan-Americana de Montevideo, em 1933, por Franklin D. Roosevelt, na época presidente dos Estados Unidos, referia-se a um período de relações políticas americanas com os países da América Latina entre 1933 até 1945, tinha entre os objetivos minimizar a influência europeia na América Latina (TOTA, 2000). Para o governo norte-americano, as Américas tinham de se transformar em uma fortaleza do hemisfério e dos próprios Estados Unidos (TOTA, 2000). "Espírito de boa vontade" e "pan-americanismo", era como o general Dunham se referia, à aproximação entre "Getúlio Vargas e Roosevelt, [...] amizade sincera que existia entre os dois povos e que se firmaria ainda mais na assistência mútua e na cooperação mútua [...]" (COOPERAÇÃO, 1943, p. 6). Intensificava-se um discurso em que a ideia era consolidar cada vez mais a necessidade de integração dos países americanos, sob a hegemonia dos Estados Unidos. Tal relação extrapolou as fronteiras políticas e passou a influenciar questões diplomáticas entre os países das Américas. Mayra Lago em artigo, demonstra como o discurso pan-americanista para a América Latina foi construído e divulgado, por exemplo, através da revista Em Guarda: para a defesa das Américas. Segundo a autora, buscava-se elaborar e propagar imagens da grande amizade entre os Estados Unidos e a América Latina e os esforços de guerra que deveriam ser postos em prática para evitar a invasão do inimigo nazista (LAGO, 2019).

George Dunham que por sinal assinava vários artigos nos Boletins do SESP, escreveu outra matéria intitulada "Dois anos de cooperação continental", na qual fazia um balanço das lutas contra as doenças e como os esforços teriam assumido dimensões continentais. Tratava-se de um empenho em justificar a ideia de que a colaboração entre os países teria favorecido 
"o trabalho no setor da saúde e concorrido para valorizar o sentido de unidade americana" (BRASIL, 1944, p. 1). Para ratificar a importância da união entre as nações no combate às doenças em tempos de guerra, seguia afirmando que "na doença, as Américas tinham um inimigo mais formidável que Hitler. Pois Hitler, como tantos candidatos ao domínio do mundo, via aproximar o seu ocaso, [...] a luta contra a doença, entretanto, não tinha um fim à vista" (BRASIL, 1944, p. 1). Entende-se que os boletins do SESP foram utilizados não apenas como um meio de informação e propaganda, mas sobretudo como instrumento de representações na construção de imagens exploradas entre os países, principalmente quando elegia as doenças como inimigo mais mortal que Hitler. Como bem nos sugere o historiador Roger Chartier, (1990, p. 17) "as representações do mundo social são construídas, e são determinadas pelos interesses de grupos que as forjam. Daí, para cada caso, o necessário relacionamento dos discursos proferidos com a posição de quem os utiliza". Dessa maneira, em tempos de guerra, os meios de comunicações como boletins e jornais eram utilizados para legitimar projetos e retratavam os inimigos que deveriam ser exterminados.

Para além do campo de batalha, acenava-se para o campo de luta da saúde como uma árdua guerra a ser vencida, e os discursos enfatizavam a necessidade de cooperação, pois "as doenças não reconheciam as fronteiras políticas e atingia a todas as pessoas, sem a distinção de raça, cor ou crença" (BRASIL, 1947, p. 1). Nesta toada, o Dr. Crispin Insaurralde, ao escrever um artigo sobre "A saúde na política do bom vizinho", enfatizou a prática da boa vizinhança no exercício da medicina e saneamento, como elemento para "estreitar laços de amizade, ampliar o horizonte do médico das Américas - o que determinaria no futuro um saneamento e uma medicina continental, no terreno social, científico e moral" (BRASIL, 1944, p. 7). A intensificação desses discursos exprimia as necessidades apresentadas pelo contexto da guerra em que exércitos aliados precisavam de matérias primas; os soldados americanos estacionados no Brasil deveriam ser protegidos das doenças tropicais; os trabalhadores envolvidos na produção da borracha e minério precisariam de prevenção contra a malária e outras doenças (CAMPOS, 2005).

Para outro norte-americano, o Dr. John Yagly, da Divisão de Saúde e Saneamento do IAIA, o programa de cooperação teria "iniciado para atender as necessidades de tempo de guerra, o trabalho prometia produzir frutos que se fariam sentir por muito tempo após a guerra" (BRASIL, 1944, p. 7). Prosseguindo, afirmava o médico que "passados mais de dois anos do início do programa, [...] milhões de trabalhadores das indústrias estratégicas nas outras Américas estavam se beneficiando das atividades de saúde e saneamento" (BRASIL, 1944, p. 3). Ao fazer referência à guerra e a luta contra as doenças que atingiam as regiões produtoras de materiais estratégicos de guerra, seguia o médico afirmando que "a luta interamericana contra a doença não era tão espetacular quanto os choques no campo de batalha. Mas, seus resultados se fariam sentir permanente nas relações entre os países do continente" (BRASIL, 1944, p. 3). Além de projetar a extensão dos serviços realizados para um contexto pós-guerra, buscava-se reforçar a necessidade de parceria entre os países, como se todos fossem dependentes das investidas norte-americanas. Estruturas médicas como os hospitais eram apresentadas como espaços das benfeitorias do SESP na batalha contra as doenças.

\section{OS HOSPITAIS PARAENSES DE BREVES E SANTARÉM}

\footnotetext{
Os edifícios inaugurados constituem, no dizer das placas de bronze que tem à entrada, 'símbolos de uma sã política de boa vizinhança'. Entretanto, seu valor é muito mais que simbólico, uma vez que eles se destinam a um papel de crescente importância na vida da comunidade. (BOLETIM No 27, 1945, p.1).
}

Deu-se a construção e inauguração dos hospitais nas cidades paraenses de Breves e Santarém, que, para além de estruturas prediais, tornaram-se símbolos forjados da política de 
boa vizinhança entre os governos do Brasil e dos Estados Unidos, e serviram para legitimar os discursos das autoridades sobre as ações que o SESP estava realizando na região. Ao chegar à cidade de Santarém para a inauguração da casa de saúde, a comitiva "via tremular as bandeiras brasileira e americana e fez-se ouvir o hino nacional brasileiro e em seguida o hino americano, entoados por uma banda de música" (FIOCRUZ, p. 23). Neste cenário, eivado de patriotismo, "os representantes cercados pelo povo", acompanharam os discursos das autoridades presentes. Durante a cerimônia, o Coronel Harold C. Gotaas afirmava ter o hospital "valor intrínseco para a população da cidade, sendo mais um passo para o desenvolvimento e progresso da saúde pública no Brasil"' (BRASIL, 1945, p. 1).

Com a inauguração da arquitetura médico-hospitalar, o coronel aproveitou para creditar aos norte-americanos, a iniciativa e liderança na agenda da saúde global. Gotaas enfatizava na cerimônia que o ato fazia "parte do programa de cooperação continental em matéria de saúde pública e saneamento, de educação e de abastecimento alimentar, em que estamos todos tão profundamente interessados" (BRASIL, 1945, p. 7). Concebido em cooperação internacional, servia o hospital como ponto de referência para creditar a parceria estabelecida entre Brasil e Estados Unidos e, a este último, legitimar suas ações junto aos países americanos. Segundo Mauad (2005, p. 45), "havia declarado interesse, por parte do Departamento de Estado dos EUA, em consolidar a presença na América Latina através de planos de cooperação internacional e alianças políticas que garantissem a hegemonia dos EUA na região".

$\mathrm{Na}$ cidade de Breves, os discursos seguiam a mesma toada. Durante a conferência de inauguração do hospital o Dr. Christopherson, reforçava a importância de contar com "habitantes saudáveis e fortes que trabalhem e produzem material estratégico e alimentos como requisitos para ganhar a guerra" (BRASIL, 1945, p. 5). A fala do representante norte-americano aliava saúde, vitória e guerra como estratégia dos EUA em estabelecer cooperação com o Brasil. Eivada de intencionalidades, tais falas seguiam uma mesma linha de raciocínio e reforçavam a importância da parceria entre os países, em prol do combate às doenças e, como consequência, o progresso e o desenvolvimento locais, evidenciando, nesse processo, a colaboração dos Estados Unidos. Desse modo, é dada, além de um protagonismo no que diz respeito ao desenvolvimento do país, a ideia de que o Brasil ficasse devedor das ações norte-americanas

Conforme estabelecido nos decretos, a instalação das arquiteturas médicas pelo interior da Amazônia contaria com a colaboração do SESP e a contrapartida das prefeituras locais. Os vários discursos das autoridades buscavam justificar as construções como novos modelos de atenção à saúde da população local, fruto da política de boa vizinhança, apontando, para isso, a ação das políticas públicas nessas localidades.

Figura 1 - Projeto do Hospital de Santarém - Pará

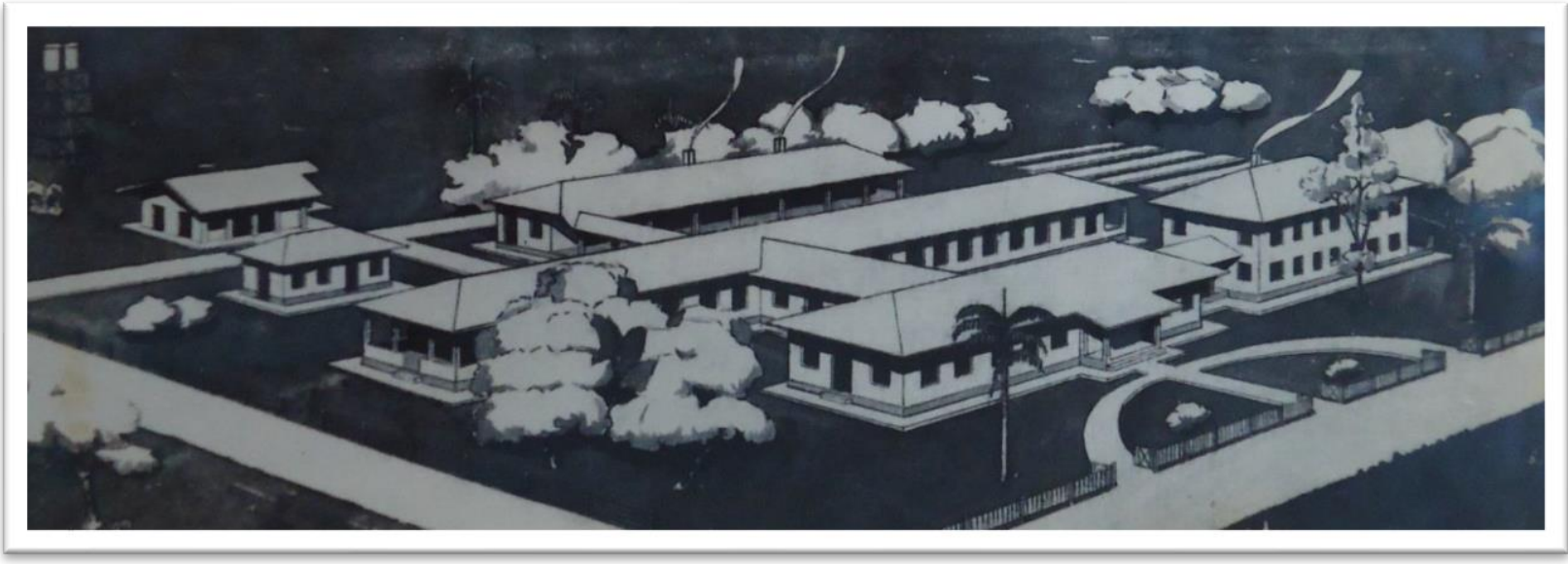

Fonte: MINISTÉRIO DA EDUCAÇÃO E SAÚDE. Postos de Higiene e Hospitais construídos pelo Serviço Especial de Saúde Pública no Estado do Pará. 1942-1945. p. 174. 
O projeto previa a construção do hospital no modelo pavilhonar. Segundo Silveira et al. (2011, p. 137), "o sistema pavilhonar manteve sua hegemonia no campo da edificação hospitalar até o início do século XX, sendo a partir de então, questionado, revisto e modificado". Esse modelo europeu foi substituído pela influência norte-americana com base no higienismo e na bacteriologia. Nessa nova estrutura, a construção em bloco único tornou-se a tônica do modelo hospitalar até hoje (COSTA, 2011). Construídos em meados do século XX, as estruturas prediais do SESP ainda seguiam os padrões da estrutura pavilhonar. A planta do hospital de Santarém mostra a organização por blocos e interligados por corredores que ligavam uma unidade à outra. Os blocos divididos poderiam ser utilizados para isolar os pacientes e seus diferentes tipos de doenças, pois "esses edifícios seguiam a tipologia organizacional e atendiam a critérios definidos pela terapia de isolamento e pela higiene dos estabelecimentos para a saúde" (COSTA, 2011, p. 130). As inúmeras janelas presentes na arquitetura contribuiriam com a iluminação e ventilação natural das salas.

Localizada na região do Tapajós, oeste do Pará, Santarém receberia a maior estrutura física do SESP. O hospital, planejado para receber 50 leitos, teria "auditório, primeiros socorros, gabinete dentário, farmácia, fisioterapia, raio X, bacteriologia, operações, pré-natal, partos, berçário, enfermaria, refeitórios, etc.” (BRASIL, 1942-1945, p. 175). Tratava-se de um hospital moderno, espaço terapêutico e "medicalizado". Na década de 1940 a cidade era "o maior empório comercial do Baixo Amazonas. Seu comércio era intenso com o país, e com o estrangeiro" (BRASIL, 1942-1945, p. 159). Contava ainda com "uma pequena indústria de construção naval, curtumes, olarias, usina elétrica, usina de beneficiamento de algodão e cereais, e muitas outras pequenas oficinas" (BRASIL, 1942-1945, p. 159). Esses elementos contribuíam para diferenciá-la da maioria das cidades amazônicas, principalmente pela dinâmica estabelecida com outros países, e poderiam ter sido fator fundamental para que o SESP pudesse construir na região um hospital de grandes proporções para a realidade do interior da Amazônia. Até a década de 1960, era comum na Amazônia a existência de pequenas cidades associadas frequentemente à circulação fluvial, o que lhes conferiam fortes ligações com a dinâmica da natureza, com a vida rural não moderna e com o ritmo da floresta ainda pouco explorada (TRINDADE JÚNIOR, 2010, p. 118).

A economia local possuía "uma agricultura com grau regular de desenvolvimento de cereais, algodão e juta. Havia pequenos seringais cultivados, indústrias extrativas de óleos vegetais, madeiras, etc. E grande indústria de pesca do pirarucu, etc.” (BRASIL, 1942-1945, p. 160). Tais atividades, principalmente as extrativas e de pesca faziam e ainda fazem parte do trabalho laboral do homem amazônico, muitos deles, essenciais para a subsistência da população, como o caso da pesca. Segundo Santos, G. Santos, A. (2005, p. 165), "a pesca é uma das atividades humanas mais importantes na Amazônia, constituindo-se em fonte de alimento, comércio, renda e lazer para grande parte da sua população, especialmente as que residem nas margens dos rios". Como outras cidades do interior amazônico, credita-se ao boom da borracha fator que assegurou a função de entreposto comercial para a cidade, reafirmando seu papel na liderança na porção oeste do Pará (OLIVEIRA, 2008). O possível potencial de extração gomífera e a dinâmica apresentada pelo município poderiam ter sido fatores para o Serviço buscar se instalar na região. Aliás, essa cidade recebeu além da maior estrutura médicohospitalar os cursos para guardas e visitadoras sanitárias, agentes de saúde com vasta atuação pelo interior da Amazônia.

Entre os anos de 1944 e 1945, o SESP realizou um inquérito no município e "malária, helmintoses, disenterias, lepra, tuberculose, bouba e úlcera tropical", eram as principais doenças que acometiam a população local (BRASIL, 1942-1945, p. 162). Sendo a região cortada por rios, muitas dessas enfermidades estariam associadas com o cotidiano dos moradores. Um exemplo, seria a úlcera tropical que "ocorria com frequência, em indivíduos 
que habitam próximos a leitos de reservatório de água, em áreas de inundações e atividades que acontecem perto dos leitos de água, como a agricultura" (BOLEIRA et al., 2010, p. 282). Medidas de combates a essas doenças estavam presentes na agenda das políticas públicas de saúde no Brasil. Nos anos iniciais da República, debates sobre o saneamento rural e as várias doenças que grassavam, sobretudo na zona rural, fomentaram a instalação dos primeiros postos de saúde e a realização das primeiras obras de engenharia sanitária (HOCHMAN, 1998). Os discursos de combates a essas doenças entraram também na agenda de atuação do SESP na Amazônia, apontando em seus inquéritos como medidas importantes a serem tomadas, como forma de uma intervenção e cuidados com as cidades e a população.

Sobre os recursos médicos em Santarém, o inquérito sanitário informava existir "três consultórios médicos e três gabinetes dentários. No interior do município, existia os dois hospitais Ford, localizados em Belterra e Fordlândia, respectivamente" (BRASIL, 1942-1945, p. 171). Essa estrutura médica teria sido construída para atender os familiares e funcionários da Ford no trabalho nos seringais (KLUSKA, 2017). Havia ainda, "o Hospital São José, mantido pela Congregação da Irmãs Missionárias da Imaculada Conceição, e subvencionado pelo governo municipal. O governo do Estado mantinha um Posto de Saúde, em Santarém" (BRASIL, 1942-1945, p. 171). Se a existência dessas casas de saúde indica a atuação de entidades privadas e filantrópicas nos cuidados da população local, a construção de um hospital sugere as ações de intervenção do Estado. Ao buscar dar publicidade, o SESP reforçava o discurso de que sua construção era "importante por sua localização, e que o edifício serviria ao mesmo tempo de hospital e Posto de Higiene". A construção "iniciada em março de 1943 e finalizada em dezembro de 1945" (BRASIL, 1942-1945, p. 171) era apresentada como uma das maiores edificações e representava a atuação do poder público e a interiorização da saúde nessa região.

Figura 2 - Vista do hospital já concluído

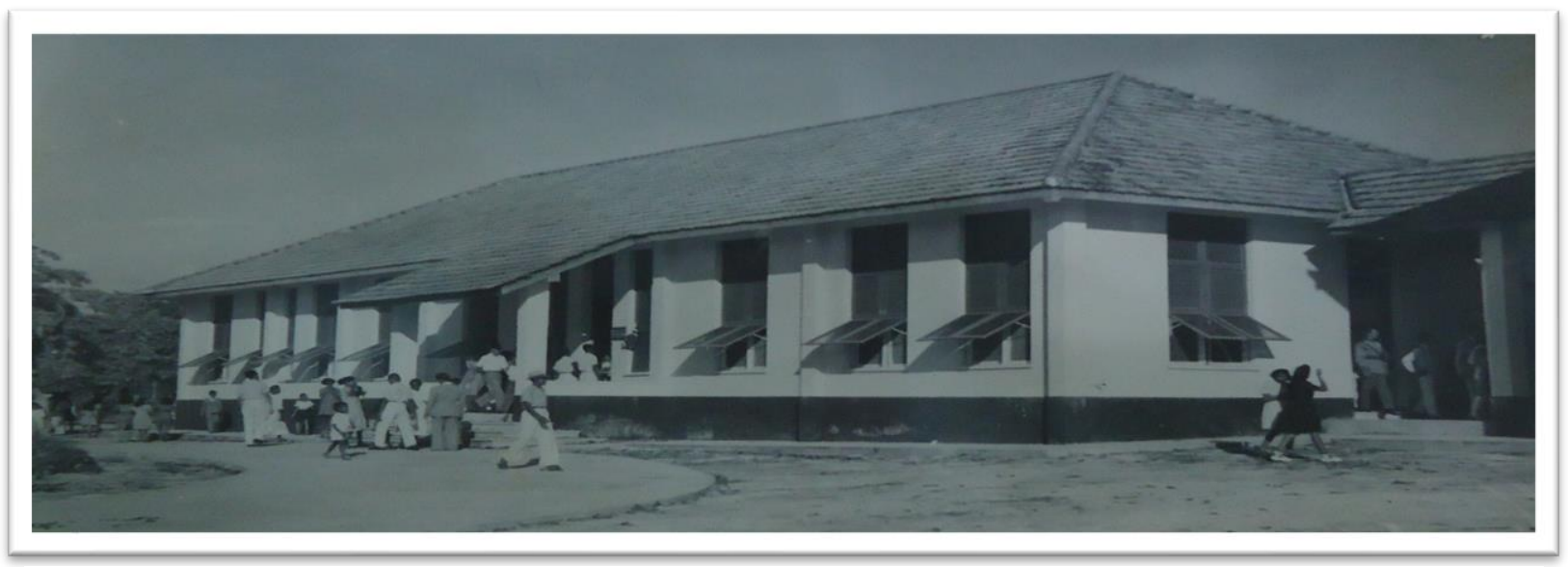

Fonte: MINISTÉRIO DA EDUCAÇÃO E SAÚDE. Postos de Higiene e Hospitais construídos pelo Serviço Especial de Saúde Pública no Estado do Pará. 1942 - 1945.

A imagem retrata a vista lateral do hospital de Santarém já concluído. De acordo com Mauad (1996, p. 11), "a fotografia pode, por um lado, contribuir para a veiculação de novos comportamentos e representações da classe que possui o controle dos meios; e, por outro, atuar como eficiente meio de controle social, através da educação do olhar". Como símbolo da política de boa vizinhança, a maior construção do SESP no interior do Pará estava pronta a ser divulgada. Era uma forma de o SESP imprimir sua marca na Amazônia e registrá-la como uma grande arquitetura que inauguraria uma nova frente de atenção à saúde pública na região. 
Segundo os dados disponibilizados, "o terreno para a construção doado pela prefeitura possuía uma área distribuída em hospital: $1.385 \mathrm{~m}^{2}$, Posto de Higiene: $425 \mathrm{~m}^{2}$, Residência das enfermeiras: $485 \mathrm{~m}^{2}$, Necrotério: $77 \mathrm{~m}^{2}$ e garagem: $153 \mathrm{~m}^{2} "$ (BRASIL, 1942-1945, p. 172). A construção de um hospital de grande porte sintetizava a presença do poder público na questão de saúde, a partir da parceira estabelecida com as autoridades políticas locais, imprimindo uma nova marca na saúde da região. Presumivelmente, depois de instalado, o hospital se tornaria a maior estrutura médica na cidade e serviria como uma forma de legitimar as ações do SESP para a população. Não à toa, o registro captura o momento na qual moradores locais, homens, mulheres e crianças transitam nos arredores do edifício. Enquanto símbolo da boa vizinhança, apresentar as pessoas em seu entorno traria um significado importante, sobretudo na divulgação das ações do Serviço.

Apesar de se tratar de uma estrutura nova e equipada, o hospital, mesmo inaugurado, parece ter encontrado dificuldades para entrar em funcionamento. Em ofício datado de fevereiro de 1946, o então prefeito da cidade, o médico sanitarista Ismael Araújo informava a Waldir Bouhid, Diretor do Departamento Estadual de Saúde, que Santarém havia irrompido um surto de palustre, e tão logo recebera um abaixo-assinado dos moradores das zonas afetadas solicitou auxílio das autoridades a fim de tomar providencias necessárias para o funcionamento do hospital (PARÁ, 1946, n.p). Ao ser pressionado pelos moradores, o prefeito cobrou agilidade para o seu funcionamento pois teria ocupado "o lugar do antigo existente, de propriedade de uma ordem religiosa que, bem ou mal, vinha servindo a população. Apesar de perfeitamente instalado, não funcionava, causando grande prejuízo aos moradores" (PARÁ, 1946, n.p).

Em poucos dias, o Diretor do Departamento Estadual de Saúde encaminhou o ofício do prefeito ao Dr. Osvaldo José da Silva, Diretor do Programa do Amazonas do SESP, e solicitou "informações exatas sobre os trabalhos do Serviço naquela região, e se possível, fossem tomadas as providencias que julgar por bem no caso em apreço" (PARÁ, 1946, n.p). Ainda no ofício afirmava "se tratar de matéria referente ao interesse público, e esclarecia que as informações que V.S. se dignar prestar-nos, seriam transmitidas ao Governo do Estado". Apesar de o documento não informar os motivos pelos quais o hospital não estava em atividade, mostrava as falhas do Serviço, pois, mesmo pronto, não atendia as necessidades da população. Privados de atendimentos médicos, moradores se mobilizaram através do abaixo-assinado exigindo o funcionamento do hospital. Provavelmente, entre eles estavam moradores presentes nas cerimônias de inauguração e ouviram os discursos dos representantes do governo com promessas de melhorias nas condições de vida. No caso de Santarém, o atraso no funcionamento do hospital poderia contribuir para o descrédito do SESP, além de mostrar, também, os anseios dos moradores pelo seu efetivo exercício no combate às doenças. Em meio à proliferação das enfermidades, coube aos moradores reclamar o atendimento médico-hospitalar junto ao poder público municipal.

Breves foi outro município paraense a receber as instalações de um hospital. A construção "era justificada pela posição estratégica da cidade, além disso, a alta incidência de doenças era outro fator a indicar a construção do hospital" (BRASIL, 1942-1945, p. 75). Rota da borracha no final do século XIX, a cidade estava em uma área estratégica. Por conta da extração do látex, o movimento comercial em Breves chamou a atenção pelo seu valor comercial, devido aos vapores atravessarem o estreito do lugar no trânsito entre Belém/Manaus (FÉLIX; NERY, 2019, p. 7). Os trabalhos tiveram início em abril de 1943 e abrangeriam, atrelados à edificação, um necrotério com capela, casa das máquinas geradoras e um sistema de abastecimento de água (BRASIL, 1942-1945, p. 75). Segundo os apontamentos dos inquéritos "foram encontradas muitas dificuldades para a construção. A não ser as pedras, areia e parte da madeira necessárias, todo o material usado na construção foi envidado de Belém" (BRASIL, 1942-1945, p. 75). Segundo Bastos (1996. p. 68), uma das formas encontradas pelo SESP para sanar as dificuldades com material, foi "arrendar a Serraria e Carpintaria 'Fluminense', 
localizada em Belém. [...] Dessa forma, o SESP acelerou a fabricação de muitas peças necessárias à instalação dos prédios construídos no interior".

Figura 3 - Projeto do Hospital de Breves - PA

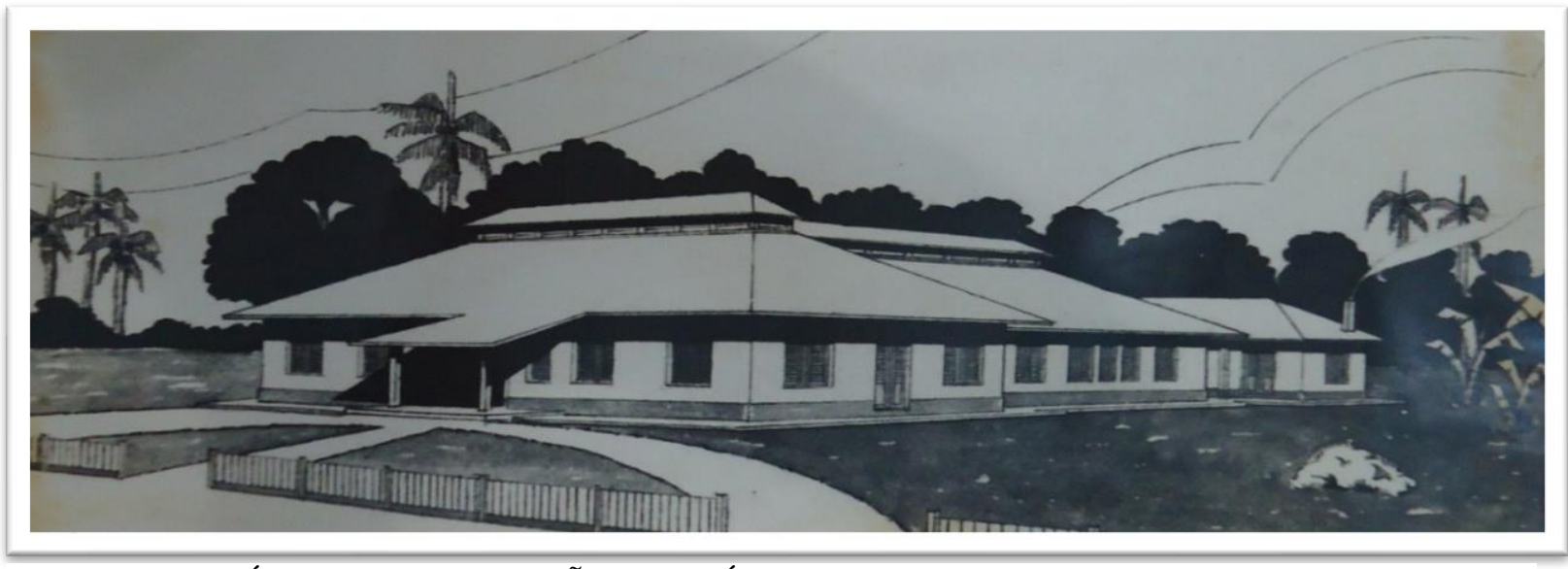

Fonte: MINISTÉRIO DA EDUCAÇÃO E SAÚDE. Postos de Higiene e Hospitais construídos pelo Serviço Especial de Saúde Pública no Estado do Pará. 1942 - 1945. p. 59.

O projeto acima previa como seria o hospital de Breves, cidade localizada na ilha do Marajó. Para a construção, a prefeitura local teria doado o terreno com "área de 9.600 metros quadrados, localizada no centro da cidade" (BRASIL, 1942-1945, p. 75). Tratava-se de um edifício com 12 leitos e sua estrutura mantinha o modelo pavilhonar, padrão nas construções do SESP. Símbolo da política de boa vizinhança, teria sido o primeiro edifício inaugurado e era apresentado como a intervenção do poder público na área da saúde na Amazônia. Durante a cerimônia de entrega, "a comitiva era esperada no trapiche por uma multidão que demonstrava o seu entusiasmo pela obra do SESP e teria acompanhado os visitantes até o local de inauguração, ouvindo atentamente os discursos e aplaudindo-os calorosamente" (BRASIL, 1945 , p. 2). Realçar a presença dos moradores locais durante os festejos não deixava de ser uma estratégia, pois poderia servir como visibilidade para políticos locais reafirmarem as medidas sanitárias em curso na cidade e dar publicidade as ações desenvolvidas pelo Serviço na região.

Sobre as condições sanitárias, a maioria das doenças presentes na cidade eram as mesmas encontradas em outros municípios amazônicos. Além da malária, apresentava índices de "helmintoses, disenterias, lepra, tuberculose, bouba e úlcera tropical" (BRASIL, 1942-1945, p. 56). Aliás, diversos esforços eram empregados no país, na organização de ações para o enfrentamento da malária. Os anos de "1930 e 1940 foram marcadas pelo surgimento de estruturas sanitárias e campanhas dedicadas ao combate à malária, levadas a cabo tanto pelo governo brasileiro, [...] como pelos esforços da fundação Rockfeller". (HOCHMAN; MELLO; SANTOS, 2002, p. 235). Breves teria sido uma das primeiras cidades do país a receber do SESP tratamentos para malária, a partir "da experiência de expurgo com o famoso DDT, um inseticida que estava revolucionando os métodos de controle da malária" (BRASIL, 1945, p. 4). Para Campos (2006, p. 130) "o sucesso desta nova técnica fez com que, cada vez mais, os responsáveis pelas políticas sanitárias acreditassem que o DDT substituiria as tradicionais formas de controle da malária". A cidade de Breves "foi a escolhida por ser um dos lugares mais assolados pela malária, em virtude de ser construída numa várzea, perto de pântanos, sobre aterros de serragem" (BRASIL, 1945, p. 4). Tais ideias reproduzem justificativas da necessidade de intervenções, sobretudo ao relacionar as más condições de moradia da cidade a um lugar insalubre e propício a todas as moléstias. 
Entre janeiro e março de 1945, foi realizado um levantamento das condições de habitação da cidade. Das 170 casas existentes na cidade, 144 foram inspecionadas, sendo "boas 57, regulares 43 e más 44". Sobre os utensílios para lavar as mãos, as residências foram classificadas como: "bons 26, regulares 6, maus 112". Em relação aos quintais, "4 foram classificados como bons, 6 regulares e 134 maus". Casas com fossas foram classificadas como: "boa 1, regulares 0 , más 29". Sobre o uso de fossas, "2 casas davam diretamente para o rio e 114 não possuíam fossas" (BRASIL, 1942-1945, p. 60). A precariedade das habitações não eram realidades apenas das cidades do interior da Amazônia. Se ainda hoje casas feitas de madeira e cobertas de palhas fazem parte do cenário de comunidades ribeirinhas, também encontramos essa estrutura na capital do Pará, principalmente nas áreas mais afastadas do centro. Através dos relatos dos moradores de Belém, na década de 1940 a estrutura da periferia apresentava "barracas, casas de pobres, casa de chão batidos [...]. Não havia água encanada e as habitações apresentavam péssimas condições de higiene e saneamento, situando-se no meio da rua sem pavimentação" (FONTES, 2002, p. 222 - 223). Os dados apresentados pelos inquéritos buscam mostrar as cidades paraenses carentes de saneamento e, ao mesmo tempo, justificar os discursos das autoridades com relação à necessidade de levar saúde e higiene para a população local.

Se os relatórios apresentados pelo SESP buscavam evidenciar a cidade como espaço cheio de problemas quanto a serviços de saneamento e condições de moradia da população, o hospital era apresentado como uma estrutura moderna, feita de alvenaria, e estaria sob gerência do Estado, apta a promover a saúde pública na região. Com "capacidade para 16 leitos, contaria com o Dr. Brasilino Ricardo de Queiroz, cinco enfermeiras - uma enfermeira chefe diplomada pela Escola Ana Neri, no Rio, e quatro outras com curso em Belém" (BOLETIM, 1945, p. 2). Além da estrutura montada, Breves contaria com profissionais da saúde - médicos e enfermeiras - e a estes somavam-se as atividades de outros agentes de saúde como os guardas e visitadoras, iniciativas consideradas importantes para a extensão do poder público em uma pequena cidade do interior da Amazônia. Não à toa, as autoridades políticas locais se apropriavam dessas ações e celebravam as intervenções realizadas. Por ocasião de sua inauguração, o Dr. Lameira Bittencourt, secretário geral do Estado, representando o Interventor Federal, teria agradecido os benefícios trazidos pelo SESP à população local e elogiou a campanha feita com o apoio do governo estadual (BRASIL, 1945, p. 2).

Economicamente, Breves contava com "7 pequenos estabelecimentos comerciais mal sortidos, uma serraria e uma usina de beneficiamento da borracha. O município produzia, borracha, madeira, oleaginosas, açúcar, couro e peles" (BRASIL, 1942-1945, p. 24). Parte das ocupações da cidade estava relacionada as riquezas naturais extraídas da região. Nos anos de 1930, com o enfraquecimento dos seringais que marcaram a história local, em função da posição estratégica e instalação de grupos empresariais, a extração da madeira impulsionou o crescimento do espaço urbano" (PACHECO, 2010, p. 10). Há de se destacar que Breves foi o município de maior produção gomífera, na região das ilhas, entre os períodos de 1900 a 1910 (WEINSTEIN, 1993). Presumivelmente, esse histórico teria impulsionado o município a ser uma das sedes escolhidas para a atuação do SESP, principalmente pelo contexto marcado pela necessidade em reativar a produção de borracha na Amazônia, dentro dos esforços de guerra.

Os hospitais construídos pelo SESP nas cidades paraenses alinhavam o discurso de promoção da saúde da população, pois "se destinavam a um papel de crescente importância na vida da comunidade" (BRASIL, 1945, p. 1). Ao mesmo tempo, reforçavam o discurso político dos tempos de guerra, como os símbolos de uma sã política de boa vizinhança.

\section{CONSIDERAÇÕES FINAIS}


Durante a III Conferência de Chanceleres ocorridas na cidade do Rio de Janeiro, Brasil e Estados Unidos celebraram uma série de acordos bilaterais. De acordo com as decisões estabelecidas ficou acordado "medidas sanitárias e de saúde adequadas, como contribuição indispensável para que os povos das repúblicas americanas pudessem assegurar seu poder defensivo e os meios de resistir à opressão" (BRASIL, 1944, p. 7). As discussões sobre saúde e o combate às doenças estavam entre as principais pautas estabelecidas nas reuniões políticas, deixando claro, também, o teor bélico do contexto, demonstrando, ao mesmo tempo, as doenças e os países do "Eixo" como principais inimigos.

Nascido durante esse contexto, o SESP atuou com uma vasta agenda na área da saúde e saneamento no país. Formação de vários profissionais como visitadoras e guardas sanitários, instalação de sentinas, abastecimento de água e, como vimos, a construção de hospitais, foram ações desenvolvidas na região amazônica. Após a realização dos inquéritos sanitários e a apresentação de um quadro desfavorável, as cidades paraenses de Breves e Santarém, receberam estruturas médicas. A construção tornou-se símbolo de uma sã política de boa vizinhança, onde os discursos alinhavam os laços de amizade e debates sobre saúde pública. Em tempos de guerra, saúde e paz contrapunham-se à ideia de doenças e nazismo. Fruto de discussões diplomáticas, a criação de agências de saúde garantiu aos Estados Unidos, por um lado, a formação de alianças no contexto da guerra e o acesso a suprimentos de recursos naturais dentro dos esforços de guerra. Por outro, possibilitou ao governo Vargas a inserção de políticas públicas na Amazônia, essenciais dentro do projeto de ampliar a presença do Estado na região. A instalação dos hospitais concretizou intervenções dos serviços públicos e o atendimento à saúde dos moradores de cidades do interior do Pará.

\section{REFERÊNCIAS}

ARGUELHES, Delmo de Oliveira. A III Conferência dos Chanceleres Americanos de 1942: o ponto decisivo da política externa getulista. Revista Brasileira de Estudos Estratégicos. Editora Luzes Comunicação, Arte \& Cultura. Rio de Janeiro. Vol. 7, nº 14, jul-dez 2015. Disponível em: http://www.rest.uff.br/index.php/rest/article/view/88/81. Acesso em: 20 jul. 2017.

BACELLAR, Carlos de A. P. Fontes documentais uso e mau uso dos arquivos. In: PINSKY, Carla Bassanezi (Org.). Fontes Históricas. São Paulo: Contexto, 2005. p. 23-80.

BASTOS, Nilo Chaves de Brito. SESP/FSESP: 1942 - Evolução histórica - 1991. $2^{\mathrm{a}}$ edição. Brasília: Fundação Nacional de Saúde, 1996.

BLOCH, Marc. Apologia da História ou oficio do historiador. Tradução André Telles. Rio de Janeiro: Jorge Zahar Ed., 2001.

BOLEIRA, Manuela et al. Úlcera de Buruli. Anais Brasileiros de Dermatologia. 2010; 85(3): p. 282. Disponível em https://www.scielo.br/pdf/abd/v85n3/a02v85n3.pdf. Acesso em: 17 set. 2020.

BRASIL. BOLETIM DO SESP. Ministério da Educação e Saúde. Rio de Janeiro. No 9. 1944.

BRASIL. BOLETIM DO SESP. Ministério da Educação e Saúde. Rio de Janeiro. No 15. 1944. 
BRASIL. BOLETIM do SESP. Ministério da Educação e Saúde. Rio de Janeiro. № 17. 1944.

BRASIL. BOLETIM do SESP. Ministério da Educação e Saúde. Rio de Janeiro. № 25. 1944.

BRASIL. BOLETIM DO SESP. Ministério da Educação e Saúde. Rio de Janeiro. No 27, outubro de 1945.

BRASIL. BOLETIM DO SESP. Ministério da Educação e Saúde. Rio de Janeiro. No 49. 1947.

BRASIL. Postos de Higiene e Hospitais construídos pelo Serviço Especial de Saúde Pública no Estado do Pará. Ministério da Educação e Saúde. 1942-1945.

CAMPOS, André Luiz Vieira de. Políticas internacionais de saúde na era Vargas: o Serviço Especial de Saúde Pública. In: GOMES, Angela de Castro. (Org.) Capanema: o ministro e seu ministério. Rio de Janeiro: Editora FGV, 2000. p. 201.

CAMPOS, André Luiz Vieira de. O Serviço Especial de Saúde Pública: políticas internacionais e respostas locais. História em Revista, Pelotas, v. 11, dezembro/2005. Disponível: https://periodicos.ufpel.edu.br/ojs2/index.php/HistRev/article/view/11585/7439. Acesso em 12 jun. 2017.

CAMPOS, André Luiz Vieira de. Políticas Internacionais de Saúde na Era Vargas: o Serviço Especial de Saúde Pública, 1942-1960. Editora Fiocruz. Coleção História e Saúde. Rio de Janeiro, 2006.

CAPELATO, Maria Helena. O Estado Novo: o que trouxe de novo? In: FERREIRA, Jorge; DELGADO, Lucilia de Almeida Neves (Orgs) O Brasil Republicano: o tempo do nacionalestatismo, do início da década de 1930 ao apogeu do Estado Novo. $2^{\text {a }}$ Ed. Civilização Brasileira, Rio de Janeiro, p. 109, 2007.

CHARTIER, Roger. A histórica cultural entre práticas e representações. Lisboa: Difel, 1990.

COOPERAÇÃO entre brasileiros e norte-americanos. Correio da Manhã, Rio de Janeiro, 7 nov. 1943.

COSTA, Renato Gama-Rosa. Apontamentos para a arquitetura hospitalar no Brasil: entre o tradicional e o moderno. História, Ciências, Saúde - Manguinhos [online] Rio de Janeiro, v.18, supl.1, dez, 2011. Disponível em: https://www.scielo.br/pdf/hcsm/v18s 1/04.pdf. Acesso em: 20 jun. 2020.

CUETO, Marcos. Saúde Global: uma breve história. Rio de Janeiro: Editora Fiocruz, 2015. ESTRATÉGIA sanitária. Diário da noite, Rio de Janeiro, 1 de dez. 1943. 
FÉLIX, Ouripson Dalvan Lopes; NERY, Elaine Lobato. A extração da borracha e a "questão social" na Amazônia: os reflexos na cidade de Breves/PA. Anais do $16^{\circ}$ Congresso Brasileiro de Assistentes Sociais. “40 anos da virada do Serviço Social”. Brasília-DF, out.-nov. 2019.

FIGUEIREDO, Cibelly Alessandra Rodrigues. Arquitetura da saúde como patrimônio. Hospital D. Luiz I da Benemérita Sociedade Portuguesa Beneficente do Pará. In: MIRANDA, C. S; COSTA, R. G. (org.). Hospitais e Saúde no Oitocentos: diálogos entre Brasil e Portugal. Rio de Janeiro: Editora FIOCRUZ, 2018.

FIOCRUZ. FSESP. Seção: Assistência médico-sanitária. Série: Unidades de Saúde. BR.FIOCRUZ.COC/FSESP/MAS/00/US/00/37. Caixa 123. Copy Daily Journal "Estado do Pará".

FONTES, Edilza Joana de Oliveira. O pão nosso de cada dia: trabalhadores e indústria da panificação e a legislação trabalhista (Belém 1940-1954). Belém: Paka-Tatu, 2002.

FONTES, Edilza. A Batalha da Borracha, a Imigração Nordestina e os Seringueiros: a relação história e natureza. In: NEVES, F. F. (org.). Faces da História da Amazônia. Belém: PakaTatu, 2006.

FOUCAULT, Michel. Microfísica do poder. Rio de Janeiro: Graal, 1995.

FUNCIONARÃO ainda este ano, no Pará, treze postos do SESP. O Jornal, Rio de Janeiro, 6 mai. 1945.

GOMES, Elane Cristina Rodrigues. A lepra e a letra: escrita e poder sobre a doença na cidade de Belém (1897-1924). 2019. Tese (Doutorado em História) - Centro de Humanidades, Universidade Federal do Pará, Fortaleza, 2019.

HOCHMAN, Gilberto. A era do saneamento: as bases da política de saúde pública no Brasil. São Paulo: Hucitec/ANPOCS, 1998.

HOCHMAN, Gilberto; MELLO, Maria Teresa Bandeira de; SANTOS, Paulo Roberto Elian dos. A malária em foto: imagens de campanhas e ações no Brasil da primeira metade do século XX. In: História, Ciências, Saúde - Manguinhos [online] Rio de Janeiro. Vol. 9 (suplemento), 2002. Disponível em: https://www.scielo.br/pdf/hcsm/v9s0/10.pdf. Acesso em: 19 jan. 2021.

KLUSKA, Caren Alessandra. A educação escolar em Fordlândia - PA e a influência da Companhia Ford Industrial do Brasil - 1931 a 1945. 2017. Dissertação. (Mestrado em Educação) - Programa de Pós-Graduação em Educação. Universidade Federal Oeste do Pará. Santarém - PA, 2017.

LAGO, Mayra Coan. Em guardas para a América e o discurso pan-americanista para a América Latina (1941 - 1945). Revista Latino-Americana de História, vol. 08, no 22 ago./dez. de 2019.

MAUAD, Ana Maria. Através da imagem: fotografia e história interfaces. Revista Tempo, Rio de Janeiro, vol. 1, nº 2, 1996. 
MAUAD, Ana Maria. Genevieve Naylor, fotógrafa: impressões de viagem (Brasil, 19411942). Revista Brasileira de História. São Paulo, v. 25, nº 49, 2005.

MIRANDA, G. TABOSA, W. Alguns aspectos dos Serviços de Saneamento na Amazônia. Revista do Serviço Especial de Saúde Pública. Fundação Serviço Especial de Saúde Pública, Rio de Janeiro, Brasil. Tomo 2, 1948.

MIRANDA, Cybelle Salvador et al. Santa Casa de Misericórdia e as políticas higienistas em Belém do Pará no final do século XIX. História, Ciência, Saúde - Manguinhos, Rio de Janeiro, v.22, n.2, abr.-jun. 2015, p. 525-539. Disponível em: https://www.scielo.br/pdf/hcsm/v22n2/0104-5970-hcsm-2015005000006.pdf . Acesso em: 28 jan. 2020.

MIRANDA, Cybelle Salvador. Hospitais na Belém Oitocentista: classicismo e diálogo entre matrizes luso-brasileiras. In: MIRANDA, Cybelle Salvador; COSTA, Renato da Gama-Rosa. (org.). Hospitais e Saúde no Oitocentos: diálogos entre Brasil e Portugal. Rio de Janeiro: Editora FIOCRUZ, 2018.

OLIVEIRA, J. M. G. C. Expansão urbana e periferização de Santarém-PA, Brasil: questões para planejamento urbano. In: X Colóquio Internacional de Geocrítica. Diez años de cambios en el mundo, em la geografia y em las ciências sociales, 1999-2008, Barcelona. Anais [....]. Universidade de Barcelona, 2008.

PACHECO, Agenor Sarraf. Portos de Memórias: cotidiano, trabalho e história no Marajó das florestas. Revista Movendo Ideias. Vol. 15, No 1 - janeiro a junho de 2010.

PARÁ. Arquivo Público do Estado do Pará. Correspondência enviada ao Diretor do Departamento Estadual de Saúde. Fundo: Saúde. Folha avulsa, Belém, 13 de fevereiro de 1946.

RODRIGUES, Silvio Ferreira. DA CARIDADE À CIÊNCIA: a assistência à saúde pública no Pará entre os séculos XIX e XX. Revista Espacialidades. [online]. 2021.1, v.17, n.1. Disponível em: https://periodicos.ufrn.br/espacialidades/article/view/22092/13941. Acesso em: 05 abr. 2021.

SANTOS, Geraldo Mendes dos; SANTOS, Ana Carolina Mendes dos. Sustentabilidade da pesca na Amazônia. Revista Estudos Avançados, nº 19, (54), 2005.

SARGES, Maria de Nazaré. Belém: Riquezas produzindo a Belle Époque (1870-1912). $3^{\text {a }}$ edição. Editora Paka-Tatu. Belém, 2010.

SANGLARD, Gisele. A construção dos espaços de cura no Brasil: entre a caridade e a medicalização. Revista Esboços: história em contextos locais. Florianópolis-SC. v. 13, n.16, 2006.

SILVEIRA, Anny Jackekine Torres. FIGUEIREDO, Betânia Gonçalves. A saúde em Minas Gerais durante o século XIX. In: História da Saúde em Minas Gerais: Instituições e Patrimônio Arquitetônico (1808-1958). SILVEIRA, A. J.T; FIGUEIREDO, B. G; MARQUES, R. C. (orgs.). Barueri, SP: Minha Editora, 2011. 
TOTA, Antonio Pedro. O Imperialismo Sedutor: a americanização do Brasil na época da Segunda Guerra. São Paulo: Companhia das Letras, 2000.

TRINDADE JÚNIOR. Saint-Clair Cordeiro da. Cidades na floresta: os "grandes projetos" como expressões do meio técnico-científico informacional no espaço amazônico. Revista IEB, $\mathrm{n}^{\circ}$ 50, set./mar., 2010.

VIEIRA, Elis Regina Côrrea. Manchete do dia: imprensa paraense e saneamento rural (1917-1924). 2016. Dissertação. (Mestrado em História) - Programa de Pós-Graduação em História Social da Amazônia. Universidade Federal do Pará. Belém - PA, 2016.

WEINSTEIN, Barbara. A Borracha na Amazônia: Expansão e Decadência (1850-1920). São Paulo: Editora HUCITEC/USP, 1993. 